\section{EXPLORANDO ATIVIDADES LÚDICAS, EXPERIMENTOS E MODELAGEM: SOLUÇÃO PARA O ENSINO E APRENDIZAGEM DE SOLUÇÕES?} Exploring play activities, experiments, and modeling: solution for teaching and learning
Solutions?

Explorando actividades lúdicas, experimentos y modelado: solución para la enseñanza y aprendizaje de Soluciones?

\begin{abstract}
Resumo
Práticas alternativas à abordagem tradicional vêm se tornando uma realidade no ensino de Química. O lúdico na perspectiva Histórico-Cultural é um caminho para a elucidação de práticas inovadoras que incentivem o interesse em aprender Química. Do mesmo modo, o uso de experimentos e modelos, promovem interações sociais primordiais para a apropriação cultural. Neste trabalho, foram empreendidas ações e discussões no âmbito da Ludicidade tendo como recursos a experimentação e modelagem. Neste intuito, utilizou-se os três momentos pedagógicos de Delizoicov na mediação do ensino do conteúdo de Soluções e Misturas para alunos da $2^{\underline{a}}$ série do Ensino Médio de uma escola estadual. Esta abordagem evidenciou que é possível combinar instrumentos e que atividades lúdicas, quando elaboradas com intenção pedagógica, contribuem com a aprendizagem.
\end{abstract}

Palavras-Chave: Ludicidade; Experimentação; Modelagem; Aprendizagem.

\begin{abstract}
Practices alternative to the traditional approach have become a reality in the teaching of Chemistry. Playfulness in the historical-cultural perspective is a way for elucidate innovative practices that stimulate the interest in learning Chemistry. In the same way, the use of experiments and models, promote social interactions primordial for the cultural appropriation. In this work, actions and discussions were undertaken in the ambit of playfulness, having as resources experimentation and modeling. In this sense, the three pedagogical moments of Delizoicov were used in the mediation Solutions and Mixtures content teaching for students of the second year in a state high school. This approach showed that it is possible to combine instruments and that play activities, when elaborated with pedagogical intent, contribute to learning.
\end{abstract}

Keywords: Playfulness; Experimentation; Modeling; Learning.

\section{Resumen}

Las prácticas alternativas al el enfoque tradicional se han convertido en una realidad en la enseñanza de química. El lúdico en la perspectiva histórico-cultural es un camino para la elucidación de prácticas innovadoras que incentiven el interés en aprender Química. De igual modo, el uso de experimentos y modelos, promueven interacciones sociales primordiales para la apropiación cultural. En este trabajo, se emprendieron acciones y discusiones en el ámbito de la ludicidad teniendo como recursos la experimentación y modelado. En este sentido, se utilizaron los tres momentos pedagógicos de Delizoicov en la mediación de la enseñanza del contenido de Soluciones y Mezclas para alumnos de la $2^{\underline{a}}$ serie de la Educación Secundaria de una escuela estatal. Este enfoque evidenció que es posible combinar instrumentos y que actividades lúdicas, cuando elaboradas con intención pedagógica, contribuyen con el aprendizaje.

Palabras clave: Ludicidad; Experimentación; Modelado; Aprendizaje.

\section{AUTORES:}

CAROLINA SANTOS BONFIM ${ }^{1}$

ORCID 0000-0001-8271-4098

${ }^{1}$ Universidade Federal da Bahia (UFBA)

JOSÉ JOAQUIM DO

AMARAL FILHO²

ORCID 0000-0001-9631-8002

2 Escola Estadual

Deputado Manoel

Novaes

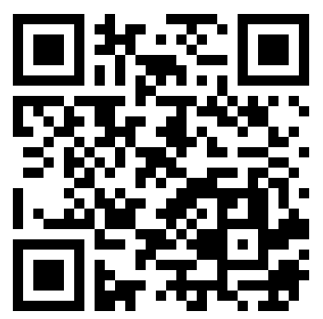

Para citar este artigo:

BONFIM, C. S.; FILHO, J. J. A. Explorando atividades lúdicas, experimentos e modelagem: solução para o ensino e aprendizagem de soluções?. Revista Eletrônica Ludus Scientiae, Foz do Iguaçu, v. 02, n. 02, p. 57-70, jul./dez. 2018. 


\section{INTRODUÇÃO}

A assimilação do conhecimento pode se dar sistemática ou espontaneamente, sendo a escola responsável por propiciar a primeira delas através do ensino institucional formalizado, enquanto que a assimilação espontânea se dá no convívio social através das relações estabelecidas socialmente. A prática libertadora e o lúdico representam inserções dos conhecimentos adquiridos pelas relações culturais na prática pedagógica, portanto lúdico e o ensino formal não caminham em vias opostas. Ao contrário, seus interesses convergem, já que as atividades passam a ser executadas com prazer e o jogo é destinado a um propósito específico (LEITE, 1999).

Na escola estadual onde a presente pesquisa foi desenvolvida, a $2^{\underline{a}}$ série do Ensino Médio tem seu conteúdo organizado em três unidades. Na terceira e última unidade, os alunos encontram-se em ritmos diferentes: enquanto alguns já foram aprovados, outros se consideram efetivamente reprovados. Em síntese, os educandos estão desanimados nesse período. Em casos como este, metodologias tradicionais não contribuem, uma vez que os estudantes têm mais dificuldade para contextualizar os conteúdos abordados. $\mathrm{O}$ intuito foi elaborar uma estratégia pedagógica que tivesse como principal objetivo apreender o interesse dos estudantes por meio da utilização de variados instrumentos (atividades lúdicas, experimentos e modelagem) e, ao mesmo tempo, possibilitar o entendimento da Química em seus diferentes níveis de compreensão.

A sequência didática proposta, tem como tema: água, a fonte da vida e como pontos de partida as questões da água em seus diversos ambientes, poluição, seus ciclos e importância socioeconômica, e foi elaborada com base nos Três Momentos Pedagógicos de Delizoicov et al. (2011): (i) Problematização Inicial, (ii) Organização do Conhecimento e (iii) Aplicação do Conhecimento. Esta delimitação foi proposta sob uma perspectiva freireana (Paulo Freire, 1921-1997), uma vez que a dinâmica organizacional se baseia em tal abordagem e é estabelecida na relação dialógica-dialética, prevalecendo o diálogo e a interação em conjunto, na qual o educador também aprende com o processo, aqui trazida em consonância com a abordagem vigostkiana. Apesar de suas particularidades, Marques e Marques (2006) salientam confluências teóricas entre Freire e Vygotsky, uma delas consiste na concepção de sujeito, interpretado como fruto do contexto histórico-cultural.

Esmiuçando os três momentos de Delizoicov et al. (2011), a problematização inicial consiste em apresentar aos educandos situações reais do cotidiano, em geral, conhecidas ou vivenciadas por eles. O professor, a partir de indagações desafiadoras que os instigam a opinar, traz os conhecimentos prévios dos alunos, o chamado "senso comum". Outras questões são colocadas adiante de modo a fazer com que o educando se sinta disposto à aquisição dos conhecimentos científicos. Para que, no segundo momento, ocorra a mediação e o senso comum seja transformado em conhecimento científico, através das atividades lúdicas e experimentos. No terceiro momento, estas atividades assim como a modelagem, servirão para aplicar e avaliar a aquisição dos conhecimentos científicos, como proposto na presente pesquisa.

Portanto, este trabalho tem como objetivo avaliar a aprendizagem do conteúdo de Soluções e Misturas diante de uma abordagem Lúdica Contextualizada sob o viés Histórico-Cultural. A estrutura da sequência, bem como os resultados e discussões estão dispostos nas próximas seções.

\section{Ludicidade e a abordagem Histórico-Cultural}

Já é sabido que o Lúdico desperta a motivação. Deste modo, a compreensão dos seus aspectos teóricos e práticos é necessária para o desenvolvimento de práticas pedagógicas. Neste sentido, despertar o interesse é fundamental para aprendizagem. Sendo o interesse compreendido como "o envolvimento interior que orienta todas as coisas, todas as nossas forças no sentido do estudo do objeto", como afirma Vygotsky (2001a, p. 192). Além do interesse, os jogos e as atividades lúdicas, por exemplo, podem estimular a memória voluntária, imaginação e a atenção voluntária dos alunos, ou 
seja, é a fonte do desenvolvimento (VYGOTSKY, 2012). De acordo com Giardinetto e Mariani (2007), $\mathrm{o}$ ato de jogar envolve suas diversas funções psicológicas superiores, independentemente da idade.

Nesta perspectiva, Vygotsky (1994) sinaliza que ludicidade e aprendizagem formal funcionam como âmbitos de desenvolvimento. O lúdico proporciona o estabelecimento de laços entre processos psicológicos e imaginários. Além de gerar a zona de desenvolvimento proximal, que se refere ao que a criança é capaz de fazer em conjunto com o sujeito mais apto, à medida que seu desenvolvimento a partir dessa interação com o mais capaz proporcionará autonomia (VYGOTSKY, 2001a). As atividades lúdicas, bem como os jogos favorecem as interações sociais, pois os sujeitos partem de uma ação individual para uma ação conjunta, de modo que tais interações propiciam a apropriação cultural, com a qual o homem se torna ser humano.

Trabalhos mais recentes, adotam a terminologia Zona de Desenvolvimento Iminente (ZDI) ao invés de Zona de Desenvolvimento Proximal (ZDP) por ser mais próxima ao significado em russo nas obras de Lev Semyonovich Vygostsky, como sugerido por Prestes (2010). Opta-se aqui em manter a expressão ZDP, unicamente para corresponder à nomenclatura utilizada na fonte citada.

A linguagem é primordial para a existência do jogo. Em uma dada situação lúdica, a linguagem é a ferramenta utilizada para a criação da brincadeira, assim "é no brinquedo que a criança aprende a agir numa esfera cognitiva, dependendo das motivações e tendências internas, e não dos incentivos fornecidos pelos objetos externos" (VYGOTSKY, 1994, p. 110).

Segundo Kishimoto (1996), o jogo tem três níveis de diferenciação: é resultado de um sistema linguístico, apresenta um sistema de regras e é um objeto. Jogo distingue-se de atividade lúdica, porque a atividade lúdica não precisa contemplar esses três níveis, e pode ser caracterizada como uma ação que gera um mínimo de divertimento. Em relação à função do jogo, o autor relata que o educador deve equilibrar ambas as funções, lúdica e educativa, de modo que uma não supere a outra, o que torna complexo o processo de elaboração e avaliação da capacidade educativa de um jogo ou atividade lúdica.

Referente ao ensino da Química, Messeder-Neto e Moradillo (2016) afirmam que o Lúdico na perspectiva Histórico-Cultural é primordial para embasar as práticas pedagógicas em salas de aula, visto que a ludicidade ainda é esvaziada de pressupostos teóricos. Na ausência de um referencial teórico, os jogos (bem como as atividades lúdicas) são elaborados de forma intuitiva, não sendo devidamente explorados.

\section{Experimentação e Modelagem}

Em relação às atividades experimentais, Hodson (1985) exalta três aspectos da experimentação no Ensino de Ciências: proposta do experimento, procedimento experimental e resultados obtidos. Cada um destes aspectos tem funções pedagógicas diferenciadas. Ainda segundo o autor, é importante salientar que há distinções entre os experimentos realizados pelos cientistas e as práticas de laboratório realizadas nas escolas (HODSON, 1988).

O procedimento experimental é aqui visto como, além de ser importante para a compreensão da própria ciência, também passível de despertar a motivação dos alunos em aprender. Contudo, o trabalho experimental precisa ser bem elaborado, para não transmitir uma ideia ingênua e neutra da observação e do próprio experimento em si, ou seja, uma concepção empirista-indutivista de ciência (LOBO, 2012). Concepção esta, característica do contexto Histórico-Cultural da produção do conhecimento científico.

De acordo com Johnstone (1993), a aprendizagem da Química envolve a compreensão e interligação de seus diferentes níveis de representação: (i) a observação dos fenômenos naturais (universo macroscópico); (ii) a representação destes em linguagem científica (universo simbólico); (iii) 
e o real entendimento do universo das partículas como átomos, íons e moléculas (universo microscópico). O autor é contrário a apresentar os três níveis de representação simultaneamente, pois o cérebro não consegue lidar com eles e propõe um desenvolvimento gradual dos níveis interconectados, ideia aqui endossada no desenvolvimento e execução da sequência. Os três níveis de representação de Johnstone encontram-se na Figura 1.

O próprio Johnstone, anos depois, modificou os vértices deste triângulo, promovendo uma reorganização nos vértices do triângulo: (i) macro e tangível, (ii) molecular e invisível, (iii) simbólico e matemático, sem haver uma relação hierárquica entre eles (MELO, 2015).

Pesquisadores, em alguns trabalhos, tecem modificações e críticas a respeito da abordagem proposta por Johnstone. Muitas destas críticas estão centradas na assunção de que esta não é a melhor forma de representar as características inerentes à Química. Wartha e Rezende (2015) relatam estes estudos, além de sinalizarem medidas apoiadas na perspectiva Semiótica Peirciana para a superação de tais questionamentos acerca deste modelo.

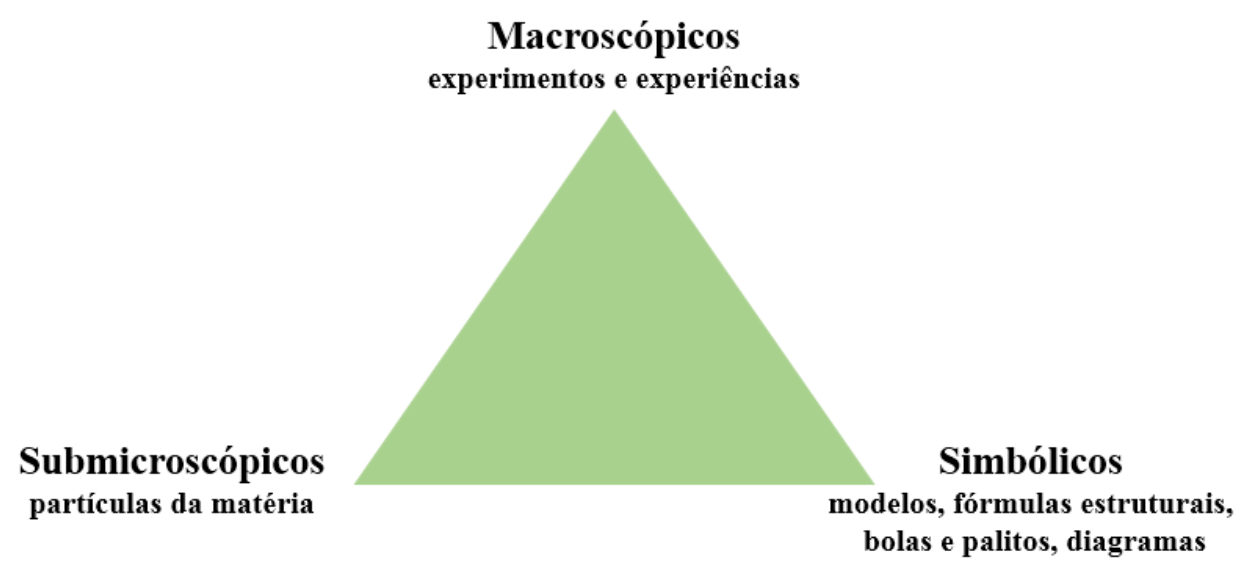

Figura 1: Níveis de compreensão do conhecimento químico (triângulo de Johnstone). Modificado de Johnstone $(1982,1993)$.

A construção de modelos, um dos instrumentos utilizados nesta pesquisa, visa motivar tanto o interesse pelo conteúdo a ser discutido quanto as relações sociais, através de uma atividade realizada em grupo, a partir da representação de estruturas e fenômenos associados ao processo de dissolução em água. Do mesmo modo, a modelagem propicia condições para que o estudante reconheça, utilize, interprete e proponha modelos para resoluções de problemas, fenômenos, sistemas naturais e/ou tecnológicos, como trazido nos Parâmetros Curriculares Nacionais (BRASIL, 2002).

Um modelo "é uma representação parcial de uma entidade, elaborado com um, ou mais, objetivo(s) e que pode ser modificado" (GILBERT et al., 2000 traduzido por JUSTI, 2010, p. 211). De forma ampla, é por meio de modelos que a Química enquanto ciência vem sendo construída, o que evidencia a importância do entendimento e da representatividade dos modelos químicos.

Mozzer et al. (2007) sumarizaram as principais concepções (alternativas) dos alunos a respeito do tema interações moleculares: compreensão das ligações químicas como entidades físicas, entendimento de que ligações químicas precisam e liberam energia quando se formam ou se quebram, respectivamente e, por fim, equivalência entre forças intermoleculares e ligações covalentes intramoleculares.

\section{O PERCURSO METODOLÓGICO}

Após a sua elaboração, a sequência didática foi aplicada em uma turma com trinta estudantes da 2 $2^{\underline{a}}$ série do Ensino Médio. Foi abordado o conteúdo Soluções, Misturas e Agregados, como proposto 
no livro didático Química Cidadã, volume 2 (SANTOS e MÓL, 2010), durante a terceira unidade, totalizando 12 encontros de 100 minutos cada, como detalhado no Quadro 1.

A sequência didática foi estruturada com base nos Três Momentos Pedagógicos de Delizoicov et al. (2011). No primeiro momento o tema da sequência foi trazido à tona durante a atividade lúdica intitulada "Dinâmica da Teia" visando conhecer as concepções prévias dos educandos. Esta dinâmica é amplamente utilizada por professores do ensino básico como forma de facilitar a interação, estabelecer um vínculo professor-aluno e reforçar a importância da assiduidade. No Quadro 2 são descritos os passos para a realização da dinâmica da teia.

Quadro 1: síntese da sequência aplicada. As cores correspondem às atividades expostas nos demais quadros.

\begin{tabular}{|l|l|l|}
\hline $\begin{array}{l}|c| \\
\text { No de } \\
\text { encontros }\end{array}$ & \multicolumn{1}{|c|}{ Conteúdo } & \multicolumn{1}{|c|}{ Aço pedagógica } \\
\hline $\mathbf{1}$ & $\begin{array}{l}\text { Conhecimentos prévios - tema “água, } \\
\text { poluição e seus ciclos }\end{array}$ & Dinâmica da teia \\
\hline $\mathbf{2}$ & Composição química & Leitura de rótulos de águas minerais \\
\hline 3 & $\begin{array}{l}\text { Conceito, definição e diferenciação entre: } \\
\text { material, substância e mistura }\end{array}$ & Jogo dos materiais \\
\hline 4 & $\begin{array}{l}\text { Conceitos de fases, soluções, misturas e } \\
\text { agregados }\end{array}$ & Estudo dirigido e prática de laboratório \\
\hline 5 & Coloides & Prática de laboratório: efeito Tyndall \\
\hline 6 & Concentração, teor e título & Aula expositiva (Datashow) \\
\hline 7 & Densidade & Aula expositiva e Jogo do afunda ou não afunda? \\
\hline 8 & Fases de tratamento da água & Teste em dupla e aula expositiva \\
\hline 9 & Revisão e conceito de modelos & Dinâmica da teia \\
\hline 10 & $\begin{array}{l}\text { Forças intermoleculares: trabalhando a } \\
\text { modelagem }\end{array}$ & $\begin{array}{l}\text { Construção de estruturas usando palitos e bolas de } \\
\text { isopor }\end{array}$ \\
\hline 11 & Diluindo as dúvidas & Aula expositiva \\
\hline 12 & Prova & \\
\hline
\end{tabular}

Quadro 2: atividade lúdica Dinâmica da teia. Fonte: autores.

\begin{tabular}{|l|l|}
\hline № & Etapas \\
\hline $\mathbf{1}$ & Estudantes ficam dispostos em círculo, preferencialmente sentados no chão junto com a professor/a \\
\hline $\mathbf{2}$ & É entregue um rolo de barbante ou fita a um deles \\
\hline 3 & $\begin{array}{l}\text { É solicitado que o/a aluno/a faça uma breve apresentação sobre si: nome, idade, se gosta de estudar } \\
\text { Química e o que já ouviu falar sobre soluções... }\end{array}$ \\
\hline 4 & $\begin{array}{l}\text { Após a apresentação, ele/a passa o rolo para outro/a estudante, o mais distante possível, segurando a } \\
\text { ponta do cordão. }\end{array}$ \\
\hline
\end{tabular}

As discussões foram limitadas aos encontros em que ocorreram as atividades lúdicas, experimentais e de modelagem. No segundo momento, como conteúdos foram contemplados: classificação dos materiais de acordo com a aparência a olho nu (homogêneos e heterogêneos); fases e misturas na atividade lúdica Jogo dos materiais, sistematizada no Quadro 3. As atividades desenvolvidas no laboratório lidaram com os temas: sistema, fase, solução, mistura, agregado e coloides. Os procedimentos experimentais encontram-se no Quadro 4. 
Quadro 3: atividade lúdica Jogo dos materiais. Fonte: autores.

\begin{tabular}{|l|l|}
\hline № & Etapas \\
\hline 1 & $\begin{array}{l}\text { O educador dispõe para a turma diversos materiais domissanitários em cima de uma mesa (pode ser } \\
\text { utilizada a mesa do professor) }\end{array}$ \\
\hline 2 & $\begin{array}{l}\text { Divide-se a sala em dois grupos. O professor chama um aluno de cada grupo por vez, eles batem par ou } \\
\text { ímpar, o que ganha escolhe um dos materiais dispostos }\end{array}$ \\
\hline 3 & $\begin{array}{l}\text { O professor pergunta: esse material é homogêneo ou heterogêneo de acordo com a aparência? Quem } \\
\text { acertar a equipe que o aluno representa ganha ponto. }\end{array}$ \\
\hline
\end{tabular}

Quadro 4: classificação, composição dos materiais e efeito Tyndall. Modificado de Santos e Mól (2010).

\begin{tabular}{|l|l|}
\hline № & Procedimento experimental \\
\hline $\mathbf{1}$ & Adicione o mesmo volume (consulte a professora) de água em cada béquer. \\
\hline $\mathbf{2}$ & $\begin{array}{l}\text { Posteriormente, adicione em cada béquer uma colher de cada material. Agite bem e deixe em repouso } \\
\text { por } 5 \text { minutos. }\end{array}$ \\
\hline 3 & Observe os sistemas, comparando-as com o primeiro que contém apenas água \\
\hline 4 & Quantas fases cada sistema apresenta? Por quê? \\
\hline
\end{tabular}

As observações foram documentadas pelos estudantes no Quadro 5. Para o efeito Tyndall, adotou-se o mesmo procedimento. Em acréscimo, foi apontado um laser em cada um dos sistemas e observou-se o comportamento do feixe de luz. No Jogo do afunda ou não afunda (Quadro 6), o conteúdo abordado foi densidade, encerrando o segundo momento da sequência. Deve-se enfatizar que os matérias sugeridos nesta atividade podem ser substituídos por outros objetos, de acordo com a criatividade e disponibilidade do/a professor/a e da turma.

Quadro 5: sistemas propostos na prática experimental a ser preenchido pelos estudantes. Modificado de Santos e Mól (2010).

\begin{tabular}{|l|l|l|l|}
\hline № & Sistema & № de fases & \\
\hline 1 & água + álcool & & \\
\hline 2 & água +xampu & & \\
\hline 3 & água + sal (NaCl) & & \\
\hline 4 & água + açúcar (sacarose) & & \\
\hline 5 & água + café & & \\
\hline
\end{tabular}

Quadro 6: Atividade lúdica Afunda ou não afunda? Fonte: autores.

\begin{tabular}{|l|l|}
\hline № & Etapas \\
\hline 1 & $\begin{array}{l}\text { Enche-se uma vasilha grande e transparente, de modo que caibam todos os materiais a serem utilizados } \\
\text { e propicie a visualização }\end{array}$ \\
\hline 2 & $\begin{array}{l}\text { O professor/a seleciona os materiais: os mesmos materiais usados nas aulas anteriores, com acréscimo } \\
\text { de: clipes, grampo de cabelo, latas de refrigerante de alumínio vazias e cheias, prendedor de cabelo, } \\
\text { lavador de vidrarias, esponja, madeira, anteparos que permitiam a entrada de água pelos seus furos, } \\
\text { palito de fósforo, objetos de ferro, latão e anel de prata. }\end{array}$ \\
\hline 3 & $\begin{array}{l}\text { O professor/a questiona: afunda ou não afunda? Por que? A partir de suas respostas, é iniciada a } \\
\text { discussão e a explicação juntamente com os estudantes. }\end{array}$ \\
\hline
\end{tabular}


No terceiro momento, a modelagem serviu para verificar a aquisição dos conhecimentos científicos relacionados ao entendimento do processo de dissolução a nível microscópico, por meio da apresentação de estruturas químicas envolvidas na dissolução de sal e açúcar em água, salientando as forças intermoleculares presentes. $\mathrm{Na}$ avaliação da unidade, os estudantes desenharam as estruturas dos íons hidratados com base nesta atividade.

Nos demais encontros foram discutidos conceitos de mistura, agregado, soluto, solvente e classificação quanto à concentração - diluída, concentrada, saturada e insaturada, salientando aspectos microscópicos e macroscópicos, associados a cálculos de concentração e densidade.

\section{RESULTADOS E DISCUSSÃO}

Mesmo que possa ser entendida como empecilho para o planejamento e desenvolvimento de aulas, a integração de diferentes instrumentos (atividades lúdicas, experimentos e modelos), é aqui tratada como uma alternativa inovadora, porém viável. Embora, seja comum a utilização isolada de tais recursos pedagógicos, a pluralidade tende a ser vista como um obstáculo a ser evitado. Não é intenção desta pesquisa tornar a utilização da mencionada combinação de recursos obrigatória, mas apontar que é possível recombiná-los. Por exemplo, atividades lúdicas e experimentação, experimentação e modelagem ou mesmo atividades lúdicas e modelagem.

No primeiro momento, o tema da sequência didática foi trazido à tona no decorrer da atividade lúdica Dinâmica da teia, que permitiu, além de averiguar os conhecimentos prévios a respeito do conteúdo de Soluções e Misturas, uma maior aproximação entre os educandos e a professora. Soares (2004) afirma que o ato de brincar não deve ser interpretado como mera realidade objetiva, o lúdico deve ser levado em conta. Deste modo, o lúdico e a subjetividade da realidade, além abordar aspectos cognitivos, levam em consideração a afetividade. Neste sentido, Tassoni (2000) salienta que a afetividade é parte ativa do processo de aprendizagem, já que as relações na sala de aula são influenciadas por sentimentos e emoções.

Com a dinâmica da teia, os educandos evidenciaram em suas falas que tinham interesse em aulas experimentais, como pode ser notado neste depoimento:

A1: "Professora, gosto de ver as coisas acontecendo, e temos poucas aulas no laboratório, pra mim, Química tem a ver com laboratório”.

A maioria deles concordou com este discurso, a ideia de associar teoria à prática no aprendizado da Química está muito presente no imaginário dos alunos, caracterizando uma visão empírico-indutivista, como argumentado por Lobo (2012). Outra fala feita por alguns estudantes chamou a atenção: "terá cálculos?", o que explicita a repulsa por cálculos matemáticos por parte dos estudantes. Neste âmbito, Vygotsky (2001b, p. 139) assegura que: "se fazemos algo com repulsa isso significa que no futuro procuraremos por todos os meios interromper essas ocupações. Por outras palavras, o novo momento que as emoções inserem no comportamento consiste inteiramente na regulagem das reações pelo organismo”. Disto, pode-se concluir que a repulsa que os estudantes manifestam por cálculos resulta em um afastamento do real objetivo: aprender Química.

No terceiro encontro, foram trabalhados os conceitos, as definições e as diferenças entre material e substância, mistura e solução. Foram utilizadas garrafas de água mineral para exemplificar as diferenciações entre água mineral, entendida como um material, e água pura como uma substância, concomitantemente discutindo seu aspecto microscópico através de sua fórmula química e estrutural. Foi questionado aos estudantes: “A água é um material ou uma substância?”, a fim de motivar uma discussão e iniciar a aula. Após um debate, foi percebido por eles que a água pode tanto ser uma substância quanto um material, a classificação depende da forma que é encontrada e do seu grau de pureza. 
Na turma surgiram questionamentos a respeito da produção das águas minerais e a razão do uso do termo "mineral". O decorrer da aula se deu a partir destes questionamentos. Em seguida, foram introduzidos conceitos de material homogêneo e heterogêneo quanto à aparência a olho nu. Informou-se aos educandos que compreender tais conceitos seria crucial para o entendimento do Jogo dos materiais, a ser realizado na segunda parte do encontro. Ficou a cargo dos estudantes, como atividade para casa, trazer embalagens vazias de produtos domissanitários (Figura 2).

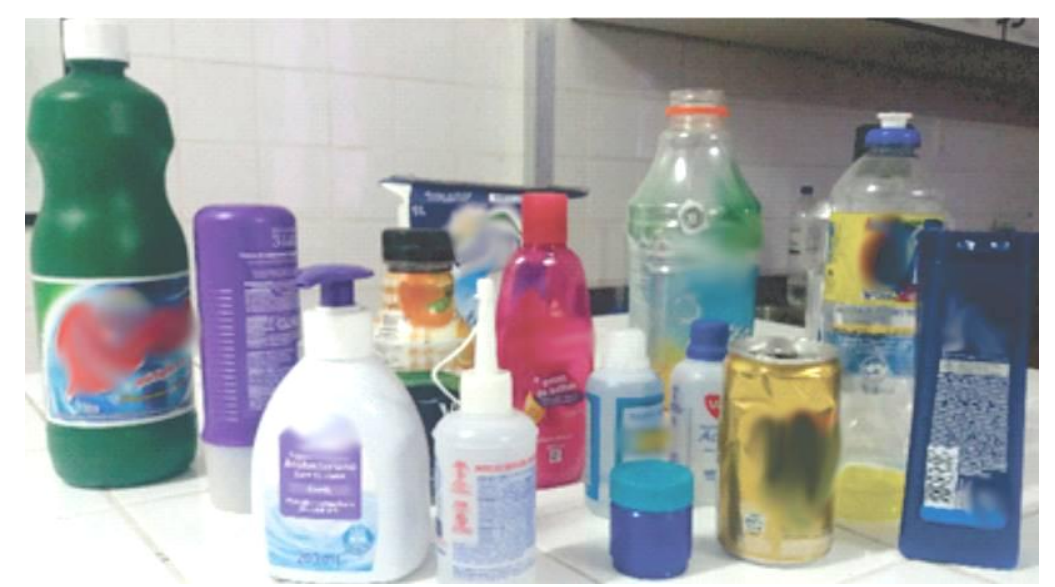

Figura 2: alguns dos itens utilizados no Jogo dos materiais. Fonte: autores.

O Jogo dos materiais serviu como uma ponte para a introdução e reforço de certos conceitos discutidos na unidade, permitindo que não se restassem dúvidas a respeito da classificação dos materiais tanto a nível macroscópico quanto microscópico. Durante o jogo, foi iniciada uma discussão sobre coloides, na qual constatou-se que alguns coloides se apresentam homogêneos a olho nu, embora sabe-se que em nível microscópico são heterogêneos.

Apesar dos nomes Jogo dos matérias, Jogo do afunda ou não afunda, estas atividades não podem ser consideradas como jogos, mas como atividades lúdicas, uma vez que não apresentam um dos níveis de diferenciação (não é um objeto), como assegurado por Kishimoto (1996). Além disso, as atividades lúdicas não apresentam regras definidas, podem ser flexibilizadas conforme as demandas do educador.

No terceiro encontro, os educandos se mostraram mais empolgados, como reflexo do Jogo dos materiais, o que contribuiu para uma execução mais dinâmica da prática de laboratório.

Com os alunos próximos à bancada, foi entregue um roteiro para cada um. Foi pedido que alguns deles lessem o procedimento experimental com o objetivo de iniciar uma discussão em grupo. Devido à limitada disponibilidade de vidrarias, a professora solicitou que alguns deles viessem à bancada para executar o procedimento experimental, enquanto os demais assistiam e teciam seus comentários. Visto incialmente como um obstáculo (nem todos fariam a parte experimental), esse formato da prática propiciou uma atividade colaborativa criando um clima mais acolhedor, além de motivar mais discussões sobre o experimento.

O sistema mais questionado pelos alunos foi o sistema 5, água mais café (Quadro 5). Enquanto forma duas fases, o café interage parcialmente por apresentar afinidade química com a água, solubilizando-se. Apesar de não prevista no planejamento inicial da aula, foi dada uma breve explicação sobre limite de solubilidade e sua relação com a temperatura, pois um aluno percebeu que ao fazer café em casa usando água quente, a água ficava bem mais escura que o sistema 5 executado no laboratório. 
Com a resolução da atividade (Quadro 5), parte respondida em laboratório e outra parte feita em casa, ficou evidente que os educandos compreenderam o significado de sistema, fases, solução, mistura (homogênea e heterogênea) e agregado, pois a maioria deles preencheu a tabela adequadamente. Inclusive, alguns deles repetiram o procedimento em casa devido à fácil disponibilidade dos materiais utilizados, além disso nenhum deles é toxico tampouco representam riscos à saúde.

No quinto encontro foi proposta uma aula no laboratório para o entendimento do conceito de coloide. Como prática experimental, repetiu-se os sistemas da aula anterior, mas nesse caso, foi incidido um feixe de luz. Os estudantes sugeriram que fossem utilizadas as lanternas dos seus celulares como alternativa ao laser e à lanterna trazida pela professora e, dessa forma, todos puderam observar o comportamento da luz.

Para a explicação sobre conceito, definição e classificação quanto à fase dispersa e dispersante dos coloides foram utilizados dois cartazes modificados de Santos e Mól (2010). Os cartazes (Figura 3) potencializaram o tempo no laboratório, além de serem objetos concretos, o que facilitou a explicação. Estes foram afixados na parede do laboratório e mantidos ao longo da unidade.

Figura 3: um dos cartazes utilizados na aula de laboratório. Modificado de Santos e Mól (2010).

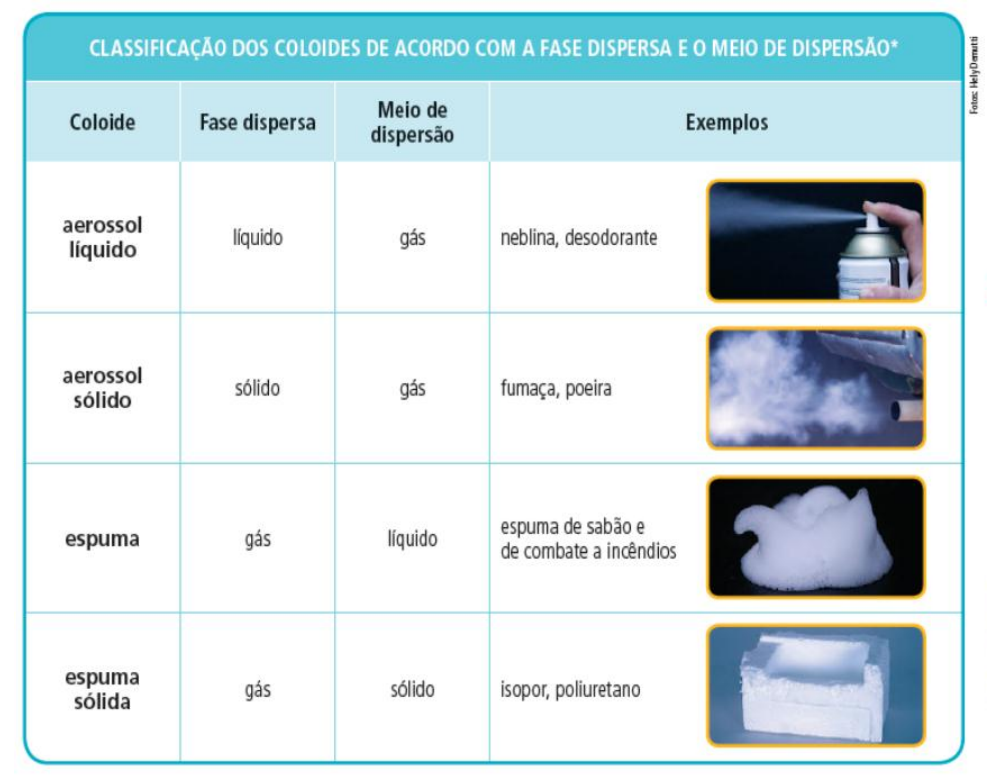

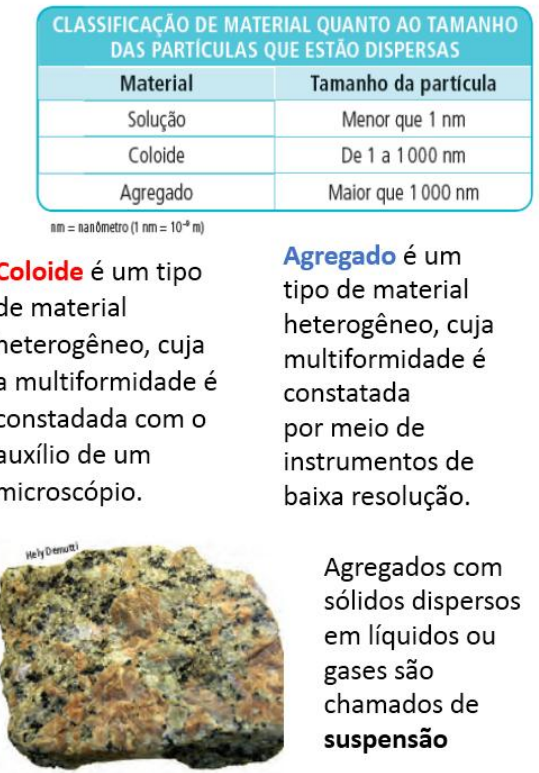

Para o fenômeno do efeito Tyndall, foram usados os mesmos materiais e sistemas do encontro anterior. Com o acréscimo de alguns materiais: xampu, gel de cabelo, álcool gel, condicionador, hidratante, creme de cabelo, xarope. Foram utilizados também materiais que não sofriam o efeito: acetona, álcool iodado, enxaguante bucal, soro fisiológico, a nível de comparação. Os educandos questionaram ao longo de toda a atividade sobre a função e utilização desses produtos.

No sétimo encontro, foram introduzidos o conceito e cálculos de densidade reforçando que seria necessário para o entendimento da atividade lúdica "Jogo do afunda ou não afunda?", a ser realizada na aula seguinte. A comparação entre as densidades do chumbo e do algodão foi feita através de cálculos e desenhos na lousa, buscando facilitar o entendimento este conceito. Foi feita pela professora a seguinte pergunta: “o que pesa mais, um quilo de chumbo ou um quilo de algodão?”. A maioria deles respondeu que o chumbo pesava mais. O questionamento, feito em tom de brincadeira, serviu de introdução para explicar o conceito de densidade e sua dependência da massa e do volume do material.

Ao elaborar uma atividade lúdica, é recomendado utilizar atividades colaborativas, de ajuda mútuas. No Jogo dos materiais os estudantes competiram entre si, já no Jogo do afunda ou não afunda? 
a sala se uniu com um objetivo em comum, se mostrando mais eficiente como jogo educativo. De acordo com Messeder-Neto e Moradillo (2016), jogos colaborativos têm muita potência no aprendizado, além de incentivar valores, importantes para a vida em sociedade. Os materiais utilizados no Jogo do afunda ou não afunda? no contexto de sua realização foram fotografados e podem ser visualizados na Figura 4.
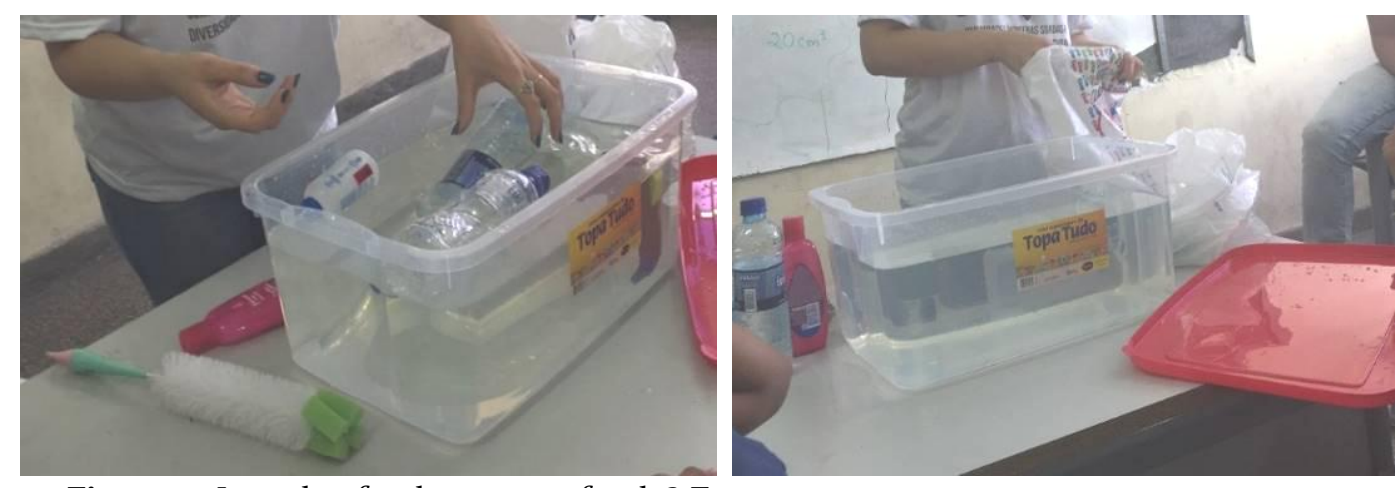

Figura 4: Jogo do afunda ou não afunda? Fonte: autores.

Foi salientado para os educandos que a densidade é uma propriedade física, experimental, intrínseca da natureza do material e varia com a temperatura. Da mesma forma, foi explicado que a água apresenta densidade padronizada como $1,00 \mathrm{~g} / \mathrm{cm}^{3}$, enfatizando que esse valor era uma aproximação já que a densidade é uma medida experimental, e que qualquer material mais denso que a água afunda e menos denso flutua. Esta explanação deu embasamento e foi utilizada como ponto de partida do jogo que foi realizado na segunda parte da aula.

A maioria dos alunos conseguiram prever o comportamento dos objetos na água. No entanto, todos tinham que justificar suas respostas baseadas nos conteúdos e materiais dados ao longo da unidade, nas aulas teóricas. A pergunta instigou os educandos e boa parte deles tentou responder, de forma assertiva ou não. $O$ interesse principal não era obter respostas corretas, mas dialogar e estimular a argumentação.

De acordo com Messeder-Neto e Moradillo (2016), as atividades lúdicas realizadas pelo homem apresentam natureza social, uma vez que aprender a jogar envolve a inserção do homem na cultura. Os jogos dependem dos contextos inseridos e são uma conquista histórica transmitidas às próximas gerações. Cientes desta assunção, as atividades lúdicas propostas foram negociadas com os alunos para evitar uma imposição cultural do professor. Da mesma forma, Soares (2013) afirma que jogos já conhecidos pelos alunos facilitam o entendimento do conteúdo, pois não se perde tempo explicando suas regras. A atividade lúdica Afunda ou não afunda? já era conhecida pelos alunos por meio de programas de televisão. No entanto, uma explicação científica para o comportamento dos objetos na água nunca fora mencionada em tais atrações.

Uma atividade em grupo foi proposta na décima aula, focada na confecção de algumas formas que representassem estruturas químicas iônicas e moleculares, dentre as quais: estrutura do cristal de $\mathrm{NaCl}$, fórmula estrutural da sacarose, estrutura da molécula de água, íon sódio hidratado, íon cloreto hidratado, solubilização do açúcar e do sal em água. Foram apresentadas diferentes representações para a dissolução de sal em água. Assim como, representações do processo de dissolução de açúcar em água foram entregues aos alunos.

Na construção dos modelos, buscou-se focar na representação das interações pertinentes ao conteúdo de soluções. Foram discutidas as relações de cargas, densidade eletrônica e ângulos de ligação. Uma tabela foi apresentada, ainda, na qual constavam as diferenças de energia entre ligações e interações químicas, de modo a promover o entendimento sobre suas diferenças. Um modelo para 
ligações químicas, disponível no laboratório da escola também foi utilizado. Portanto, ao longo das explicações tecidas, foram feitas algumas demonstrações que incrementaram as discussões.

Ainda foram exaltadas durante a explicação, as composições químicas do açúcar e do sal. Os educandos indagaram se havia alguma diferença entre os tipos de açúcar encontrados no mercado: demerara, açúcar cristal e de confeiteiro. Foi feita uma breve explicação seguindo uma abordagem sócio-histórica, de modo a contemplar as razões desses açúcares apresentarem aspectos diferentes, já que somente a Química não consegue dar conta do questionamento proposto. Nesta perspectiva, Wartha et al. (2013) asseveram que o ensino da Química deve contemplar, além do conteúdo químico, uma relação com o contexto, para proporcionar a formação de indivíduos críticos e alfabetizados cientificamente.

A atividade de modelagem consistiu em, inicialmente, dividir os alunos em grupos. Posteriormente, os estudantes escolheram e montaram as estruturas desejadas utilizando palitos de dente e bolinhas de isopor coloridas. Ficando a critério deles escolher qual forma iriam representar. Devido à sua simplicidade, o íon hidratado foi a forma mais escolhida pelos estudantes (Figura 5), contudo todas as formas foram representadas pelo menos por um grupo. Mozzer et al. (2007, p. 2) sinalizam que o processo de modelagem:

"apresenta-se como uma alternativa para o ensino de Química, que se contrapõe à ênfase na memorização desvinculada de significado, frequentemente observada no ensino tradicional. Além disso, o ensino fundamentado em atividades de modelagem insere-se no contexto de abordagens atuais que valorizam o conhecimento do estudante e a compreensão significativa dos conteúdos."

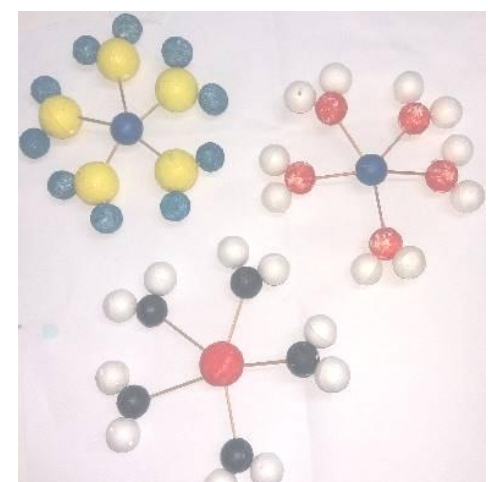

Figura 5: modelos construídos com bolas de isopor e palitos representando íons hidratados.

Fonte: autores.

$\mathrm{Na}$ avaliação final, os estudantes representaram as estruturas dos íons sódio e cloreto hidratados, com base nas diferentes representações para a dissolução de sal e açúcar entregues pela professora (Figuras 6a e 6b).
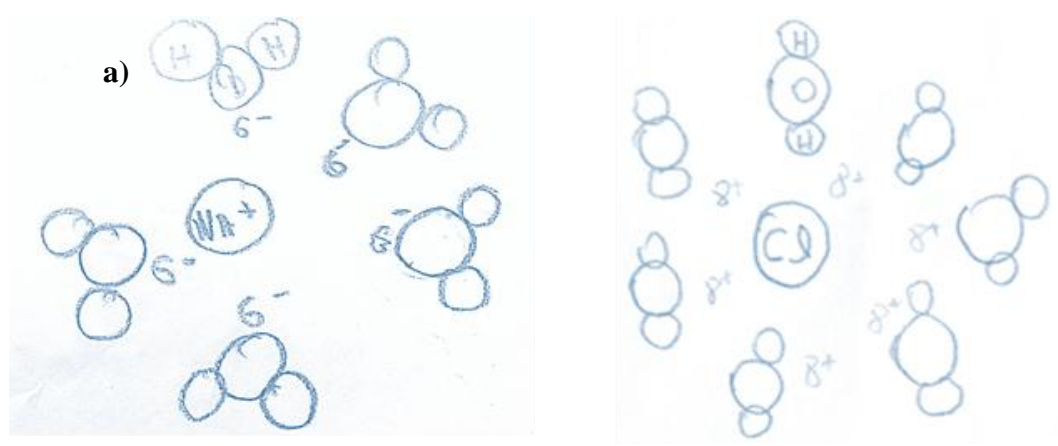

b) 


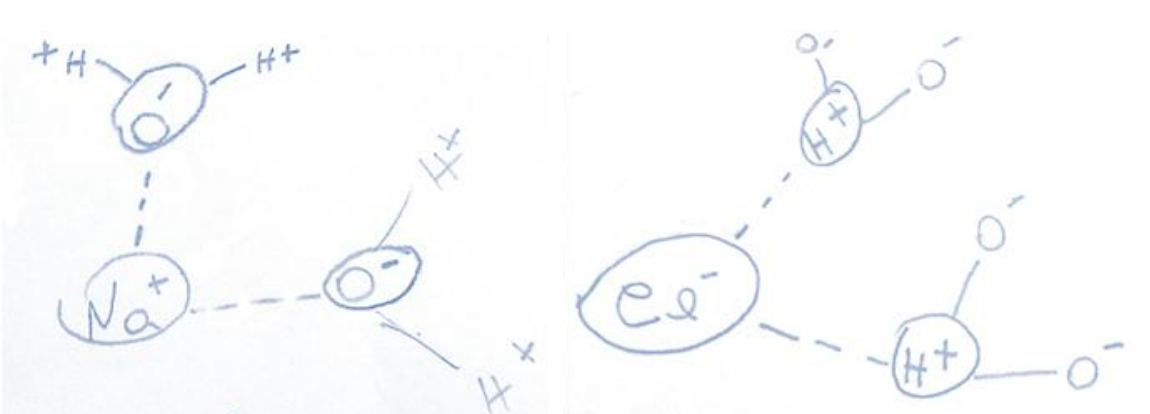

Figura 6: representações de íons hidratados desenhadas por diferentes discentes. Fonte: autores.

Como resultado foram obtidos desenhos distintos, alguns discentes diferenciaram carga parcial de carga total (Figura 6a), as orientações das moléculas de água, de forma geral, estavam adequadas. Na Figura 6b, o estudante não distinguiu as cargas e nem soube representar o balanço de cargas de acordo com a valência dos átomos, no entanto, diferenciou ligação de interação química. Mozzer et al. (2007, p. 3) apontam que uma das maiores dificuldades dos alunos é justamente a "confusão entre interações interatômicas e intermoleculares". Com base nesses desenhos, é percebido a carência de conhecimento químico básico, que deveria ter sido previamente assimilado, necessário para o entendimento de forças de ligação e interações intermoleculares.

\section{CONSIDERAÇÕES FINAIS: EXISTEM SOLUÇÕES?}

Pensar em soluções pré-concebidas é algo, no mínimo, presunçoso. O processo de ensino e aprendizagem é mais complexo do que fórmulas ou receitas a serem aplicadas. No entanto, pode-se conceber estratégias que contribuam para a inovação e, consequentemente, no avanço da prática pedagógica.

A partir da experiência com educandos da $2^{\underline{a}}$ série do Ensino Médio de uma escola estadual, admite-se que atividades lúdicas contribuem de forma significativa para a aquisição e desenvolvimento de conhecimentos científicos relacionados à Química. Contudo, devem ser tratadas como meios e não fins, ou seja, o conteúdo ainda deve ser o protagonista, durante a utilização de jogos, brincadeiras e atividades.

Atividades lúdicas, promovem a interação social, primordial para o processo de aquisição cultural, fazem refletir além de estimular o aprendizado, a memória voluntária, a imaginação e a curiosidade. É importante salientar que as atividades lúdicas têm como principal propósito incentivar o interesse pela disciplina e não somente pelo conteúdo.

Foi evidenciado que as atividades lúdicas servem de facilitadores no processo de assimilação dos conhecimentos científicos, além de promover a formação de indivíduos críticos com relação às demandas da sociedade e à própria ordem social. Os experimentos, bem como a modelagem, também são artifícios para a promoção das interações sociais e neste trabalho dão suporte à prática lúdica apoiada na Psicologia Histórico-Cultural.

Todas as atividades lúdicas propostas foram consideradas educativas, uma vez que não ocorreu o esvaziamento do conteúdo químico abordado e, por consequência, a função lúdica não superou a função educativa, como discutido por Kishimoto (1996). Isto só foi possível porque as atividades foram pedagogicamente planejadas. No entanto, deve-se salientar que o planejamento é parte essencial e, por si só, não garante o equilibro entre função lúdica e educativa.

Os modelos, bem como suas representações, serviram para compreender os níveis de entendimento dos educandos, mostrando ser um caminho eficiente para detectar interpretações equivocadas sobre o conteúdo abordado e os conhecimentos prévios dos alunos. 
No que se refere ao papel do educador e sua relação como os alunos, Vygotsky (2001b, p. 455) salienta que este "deve viver na comunidade escolar como parte inalienável dela e, nesse sentido, as suas relações com o aluno podem atingir tal força, transparência e elevação que não encontrarão nada igual na escola social das relações humanas". Ao ensinar, o educador deve despertar o encantamento pelo conhecimento. O professor é fundamental para promover a modificação da condição cultural dos alunos, sendo o ser mais capaz no processo de aprendizagem. A compreensão do ensino e aprendizagem é estabelecida com a noção de que esta não acaba na sala de aula, mas se estende a contextos sociais mais amplos.

\section{REFERÊNCIAS}

BRASIL. Parâmetros Curriculares Nacionais - PCN+ - Ensino Médio - Ciências da natureza, matemática e suas tecnologias. Brasília: Ministério da Educação, 2002.

DELIZOICOV, D.; JOSÉ, A. A.; MARTA, M. P. Ensino de ciências: fundamentos e métodos. $4^{a}$ ed. São Paulo: Cortez, 368 p. 2011.

GIARDINETTO, J. R. B.; MARIANI, J. M. O Lúdico no Ensino da Matemática na Perspectiva Vigotskiana no Desenvolvimento Infantil. In: ARCE, A.; MARTINS, L. M. (Orgs.). Quem tem medo de ensinar na educação infantil? Campinas, SP: Editora Alínea, 2007.

HODSON, D. Philosophy of Science, Science and Science Education. Studies in Science Education, v. 12, n. 1, p. $25-57,1985$.

HODSON, D. Experimentos na Ciência e no Ensino de Ciências. Tradução de Paulo A. Porto. Educational Philosophy and Theory, v. 20, p. 53-66, 1988.

JOHNSTONE, A. H. Macro and micro-chemistry. The School Science Review, v. 64, n.2, p. 377-379, 1982.

JOHNSTONE, A. H. The Development of Chemistry Teaching: A changing response to changing demand. Journal of Chemical Education, v. 70, n. 9, p. 701, 1993.

JUSTI, R. Modelos e Modelagem no Ensino da Química. In: SANTOS, W.L.P. \& MALDANER, O.A. Ensino de Química em Foco. 1eㅡ. ed. Ijuí, SC: Unijuí, p. 211, 2010.

KISHIMOTO, T. M. Jogo, brinquedo, brincadeira e a educação. São Paulo, SP: Cortez Editora, p. $208,1996$.

LEITE, G. O. Coletânea Científica. Salvador, BA: Editora Junior, p. 298, 1999.

LOBO, S. F. O trabalho experimental no ensino de Química. Química Nova, v. 35, n. 2, p. 430-434, 2012.

MARQUES, L. P.; MARQUES, C. A. Dialogando com Paulo Freire e Vygotsky sobre Educação. In: REUNIÃO ANUAL DA ANPED, 29, 2006, Caxambu, MG. Anais... Rio de Janeiro, RJ: ANPED, 2006.

MELO, M. S. A Transição entre os Níveis - Macroscópico, Submicroscópico e Representacional - uma Proposta Metodológica. 2015. 134 f. Dissertação (Mestrado Profissional em Ensino de Ciências) - Programa de Pós-Graduação em Ensino de Ciências, Universidade de Brasília, Brasília, 2015.

MESSEDER-NETO, H. S.; MORADILLO, E. F. O Lúdico no Ensino de Química: Considerações a partir da Psicologia Histórico-Cultural. Química Nova na Escola, v. 38, n. 4, p.360-368, 2016.

MOZZER, N. B.; QUEIROZ, A. S.; JUSTI, R. S. Proposta de Ensino para introdução ao tema Interações Moleculares via Modelagem. In: ENCONTRO NACIONAL DE PESQUISA EM EDUCAÇÃO EM CIÊNCIAS, 6, 2007, Florianópolis, SC. Anais...Florianópolis, SC: ABRAPEC, 2007.

PRESTES, Z. R. QUANDO NÃO É QUASE A MESMA COISA. Análise de traduções de Lev Semionovitch Vigostki no Brasil. Repercussões no campo Educacional. 2010. 295 f. Tese (Doutorado em Educacação) Programa de Pós-Graduação em Educação, Universidade de Brasília, Brasília, 2010. 
SANTOS, W.; MÓL, G. Química cidadã: materiais, substâncias, constituintes, química ambiental e suas implicações sociais. $3^{\mathrm{a}}$ ed. v. 2. São Paulo: Nova Geração, 320 p., 2010.

SOARES, M. H. F. B. O lúdico em Química: jogos e atividades aplicados ao ensino de Química. 2004, $218 \mathrm{f}$. Tese (Doutorado em Ciências Exatas e da Terra), Programa de Pós-Graduação em Ciências Exatas e da Terra, Universidade Federal da São Carlos, São Carlos, 2004.

SOARES, M. H. F. B. Jogos e atividades lúdicas no ensino de química. $2^{a}$ ed. Goiânia, GO: Kelps, p. 196, 2013.

TASSONI, E. C. M. Afetividade e produção escrita: a mediação do professor em sala de aula. 233 f. 2000. Dissertação (Mestrado em Educação). Programa de Pós-Graduação em Educação, Universidade Estadual de Campinas, Campinas, 2000.

VYGOTSKY, L. S. A formação social da mente. Tradução de Paulo Bezerra. $4^{\underline{a}}$ ed. São Paulo, SP: Martins Fontes, p. 8o, 1994.

VYGOTSKY, L. S. A construção do pensamento e da linguagem. Tradução de Paulo Bezerra. $1^{a}$ ed. São Paulo: Martins Fontes, p. 491, 2001a.

VYGOTSKY, L. S. Psicologia pedagógica. Tradução de Paulo Bezerra. São Paulo: Martins Fontes, p. 576, 2001b.

VYGOTSKY, L. S.; LURIA, A. R.; LEONTIEV, A. N. Tradução de Maria da P. Villalobos. Linguagem, desenvolvimento e aprendizagem. 11ํㅡㄹ ed. São Paulo, SP: Ícone, p. 191, 2012.

WARTHA, E. J.; SILVA, E. L.; BEJARANO, N. R. R. Cotidiano e Contextualização no Ensino de Química.

Química Nova na Escola, v. 35, n. 2, p. 84-91, 2013.

WARTHA, E. J.; REZENDE, D. B. A elaboração conceitual em química orgânica na perspectiva da semiótica Peirceana. Ciência e Educação, v. 21, n. 1, p. 49-64, 2015.

Carolina Santos Bonfim: Licenciada (2018) e Bacharela (2015) em Química pela Universidade Federal da Bahia (UFBA). Atualmente, é mestranda no Programa de Pós-Graduação em Ensino, Filosofia e História das Ciências (UFBA/UEFS). Desenvolveu pesquisas com sínteses inorgânicas, educação científica e inclusão. Tem interesse nos seguintes temas: Ensino e Filosofia das Ciências, Ensino de Química, Educação Inclusiva, Ludicidade e Experimentação.

E-mail: carol.sb88@gmail.com

José Joaquim do Amaral Filho: Licenciado em Química pela Universidade do Estado da Bahia - UNEB (1991). Especialista em Metodologia do Ensino, Pesquisa e Extensão em Educação pela UNEB e Ciências da Natureza, matemática e suas tecnologias pela Universidade de Brasília (UnB). Atua como professor da Escola Estadual Deputado Manoel Novaes e é supervisor do PIBID/UFBA.

E-mail: joaquimicamaral@gmail.com 